\title{
Interobserver variability in the delineation of the tumour bed using seroma and surgical clips based on 4DCT scan for external-beam partial breast irradiation
}

Bing Guo ${ }^{1,2}$, Jianbin $\mathrm{Li}^{{ }^{*}}$, Wei Wang ${ }^{1}$, Min Xu${ }^{1}$, Qian Shao ${ }^{1}$, Yingjie Zhang ${ }^{1}$, Chaoqian Liang ${ }^{1}$ and Yanluan Guo ${ }^{1,2}$

\begin{abstract}
Background: To explore the interobserver variability in the delineation of the tumour bed using seroma and surgical clips based on the four-dimensional computed tomography (4DCT) scan for external-beam partial breast irradiation (EB-PBI) during free breathing.

Methods: Patients with a seroma clarity score (SCS) $3 \sim 5$ and $\geq 5$ surgical clips in the lumpectomy cavity after breast-conserving surgery who were recruited for EB-PBI underwent 4DCT simulation. Based on the ten sets of 4DCT images acquired, the tumour bed formed using the clips, the seroma, and both the clips and seroma (defined as $T_{B}, T B_{S}$ and $T B_{C+S}$, respectively) were delineated by five radiation oncologists using specific guidelines. The following parameters were calculated to analyse interobserver variability: volume of the tumour bed $\left(\mathrm{TB}_{\mathrm{C}}, \mathrm{TB}_{\mathrm{S}}, \mathrm{TB}_{\mathrm{C}+\mathrm{S}}\right)$, coefficient of variation $\left(\mathrm{COV}_{C}, \mathrm{COV}_{S}, \mathrm{COV}_{\mathrm{C}+S}\right)$, and matching degree $\left(\mathrm{MD}_{\mathrm{C}}, \mathrm{MD}_{\mathrm{S}}, \mathrm{MD}_{\mathrm{C}+S}\right)$.
\end{abstract}

Results: The interobserver variability for $\mathrm{TB}_{C}$ and $\mathrm{TB}_{C+S}$ and for $\mathrm{COV}_{C}$ and $\mathrm{COV}_{C+S}$ were statistically significant $(p=0.021$, $0.008,0.002,0.015)$. No significant difference was observed for $\mathrm{TB}_{S}$ and $\mathrm{COV}_{S}(p=0.867,0.061)$. Significant differences in interobserver variability were observed for $\mathrm{MD}_{C}$ vs $M D_{S}, M_{C} v \mathrm{VD}_{C+S}, \mathrm{MD}_{S}$ vs $M D_{C+S}(p=0.000,0.032,0.008)$, the interobserver variability of $M D_{S}$ was smaller than that of $M D_{C}$ and $M D_{C+S}\left(M D_{S}>M D_{C+S}>M D_{C}\right)$.

Conclusions: When the SCS was $3 \sim 5$ points and the number of surgical clips was $\geq 5$, interobserver variability was minimal for the delineation of the tumour bed based on seroma.

Keywords: Breast cancer, Four-dimensional computed tomography, Interobserver variability, Surgical clips, Seroma

\section{Background}

Breast-conserving therapy (BCT), which involves a wide local excision followed by radiotherapy to the whole breast, is the standard treatment for early-stage breast cancer [1]. The efficacy of BCT for the treatment of earlystage breast carcinoma has been established in multiple randomised trials [2,3]. External-beam partial breast irradiation (EB-PBI) has recently garnered increasing interest $[4,5]$. Several studies reported that EB-PBI, which delivers radiotherapy to the postoperative tumour bed (TB) with a margin of adjacent breast tissue, could achieve

\footnotetext{
* Correspondence: lijianbin@msn.com

'Department of Radiation Oncology, Shandong Cancer Hospital and Institute, Jiyan Road, Jinan, Shandong Province 250117, China

Full list of author information is available at the end of the article
}

excellent results in certain patients. However, there are inherent challenges in defining accurate target volumes for partial breast irradiation (PBI). Studies demonstrate significant interobserver variability between radiation oncologists in defining the lumpectomy cavity, indicating the need to improve the accuracy and consistency in the delineation of the TB [6,7].

Surgical clips and seroma are important markers for delineating the TB for EB-PBI [7,8]. Kirby et al. [7] reported that the number of implanted markers influences the accuracy of target delineation and that five to six surgical clips are preferable for TB delineation for PBI or breast boost radiotherapy. Landis et al. [8] indicated that the shift of the centre of mass (COM) decreased and the percent volume overlap (PVO) increased significantly as the seroma clarity 
score (SCS) increased. The influence of the number of metal clips, SCS, delineation experience and contouring guidelines for the delineation of TB in CT images have been investigated $[6,7,9-11]$. However, the effect of interobserver variability on the delineation of the TB using seroma and surgical clips based on 4DCT scan is not clearly established. To investigate the impact of different markers on interobserver variability in the delineation of TB based on 4DCT scan for EB-PBI, we analysed the TB delineated by five observers in this study based on clips, seroma, and both clips and seroma.

\section{Methods \\ Patients}

Twenty patients who underwent wide-local excision of breast cancer with full-thickness unstitching of the excision cavity (10 left-sided and 10 right-sided lesions) followed by EB-PBI between June 2009 and November 2013 were included in this study. To improve the delineation accuracy and consistency, all of the enrolled patients had SCS $3 \sim 5$ and $\geq 5$ surgical clips to mark the boundaries of the lumpectomy cavity. For every patient, five or more roundish surgical clips with diameters of $2 \mathrm{~mm}$ were implanted. The surgical clips were fixed to the superior, inferior, medial, lateral, and posterior walls of the surgical cavity, respectively (median number: 6) [12]. The average interval from lumpectomy to 4DCT scan was 10 weeks (range, 3-16 weeks). All patients were free of chronic lung diseases, and their ventilation functions were normal. Written informed consent was obtained from all patients with the approval of the Institutional Review Board (Shandong Tumour Hospital Ethics Committee).

\section{Four-dimensional CT image acquisition}

All twenty patients were immobilised in the supine position on a breast board using an arm support (with both arms above the head to adequately expose the breast). 4DCT images and respiratory signals were acquired with a thickness of $3 \mathrm{~mm}$ at the conclusion of the standard CT simulation using a 16-slice Brilliance Big Bore CT scanner (Philips Medical Systems, Inc., Cleveland, OH, USA). The signals were sent to the scanner to label a time tag on each CT image. GE Advantage 4D software (General Electric Healthcare, Waukesha, WI, USA) sorted the reconstructed 4DCT images into 10 respiratory phases based on these tags, with $0 \%$ corresponding to end inhalation (EI) and 50\% corresponding to end exhalation (EE). Then, the constructed 4DCT image sets were transferred to the Eclipse treatment planning system (Eclipse ${ }^{\text {Tx }}$ 8.6; Varian Medical Systems, Palo Alto, CA) for structure delineation.

\section{Observers}

Five observers specialising in radiation treatment of breast carcinoma with more than five years of radiotherapy experience performed the delineations.

\section{Tumour bed delineation}

The 10\% 90\% phases of the 4DCT images were registered on the $0 \%$ phase images, which served as the basic phase image. The tumour beds were delineated from the ten sets of 4DCT images based on the clips, the seroma, and both the clips and seroma (termed $\mathrm{TB}_{\mathrm{C}}, \mathrm{TB}_{\mathrm{S}}, \mathrm{TB}_{\mathrm{C}+\mathrm{S}}$, respectively) according to a set of guidelines [13] (Figure 1). When the TB was delineated based on clips, we adjusted the window level and width to minimise the impact of seroma for contouring. All observers outlined a single test case that was reviewed prior to commencing the study to ensure that the guidelines were being followed.

\section{Observation parameters}

To quantify interobserver variability, the following parameters were calculated: the volume of $\mathrm{TB}\left(\mathrm{TB}_{\mathrm{C}}, \mathrm{TB}_{\mathrm{S}}\right.$, $\mathrm{TB}_{\mathrm{C}+\mathrm{S}}$ ), which was an average value generated from the ten contours of the registered images for each patient, and the interobserver coefficient of variation $\left(\mathrm{COV}_{\mathrm{C}}\right.$, $\mathrm{COV}_{\mathrm{S}}, \mathrm{COV}_{\mathrm{C}+\mathrm{S}}$ ) for each patient. The COV was defined as the ratio between the standard deviation and the average volume of $\mathrm{TB}$. For $\mathrm{TB}_{\mathrm{C}}, \mathrm{TB}_{\mathrm{S}}$, and $\mathrm{TB}_{\mathrm{C}+\mathrm{S}}$, an evaluation of the matching degree among the various observers in the EE phase was also performed. For each patient, the ratio between the intersection volume (the intersection among the volumes delineated by the five observers) and the union volume (the union among the volumes delineated by the five observers) was calculated (termed $\mathrm{MD}_{\mathrm{C}}, \mathrm{MD}_{\mathrm{S}}$ and $\mathrm{MD}_{\mathrm{C}+\mathrm{S}}$, respectively) [14] (Figure 2). The volume variability between the clips, the seroma, and both the clips and seroma based on the same observer was also calculated.

\section{Statistical analysis}

SPSS 19.0 software was used for statistical analyses. A normal distribution test and a test for homogeneity of variance were performed. To investigate the interobserver variability in the delineation of the TB based on different makers in 4DCT images, a univariate analysis of variance (ANOVA) was used to compare differences in the TB $\left(\mathrm{TB}_{\mathrm{C}}, \mathrm{TB}_{\mathrm{S}}, \mathrm{TB}_{\mathrm{C}+\mathrm{S}}\right), \mathrm{COV}\left(\mathrm{COV}_{\mathrm{C}}, \mathrm{COV}_{\mathrm{S}}, \mathrm{COV}_{\mathrm{C}+\mathrm{S}}\right)$ and $\mathrm{MD}\left(\mathrm{MD}_{\mathrm{C}}, \mathrm{MD}_{\mathrm{S}}, \mathrm{MD}_{\mathrm{C}+\mathrm{S}}\right)$ between observers. The volume variability between the $\mathrm{TB}_{C}, \mathrm{~TB}_{\mathrm{S}}$ and $\mathrm{TB}_{\mathrm{C}+\mathrm{S}}$ was also compared using ANOVA. $\mathrm{P}<0.05$ was considered significant.

\section{Results}

TB volume

The volumes of $\mathrm{TB}_{C}, \mathrm{~TB}_{S}$ and $\mathrm{TB}_{\mathrm{C}+\mathrm{S}}$ are listed in Table 1 . The average volumes of $\mathrm{TB}_{\mathrm{C}}, \mathrm{TB}_{\mathrm{S}}$ and $\mathrm{TB}_{\mathrm{C}+\mathrm{S}}$ were 21.98 cc (range 8.70-45.13), 14.36 cc (range 3.14-41.80), 


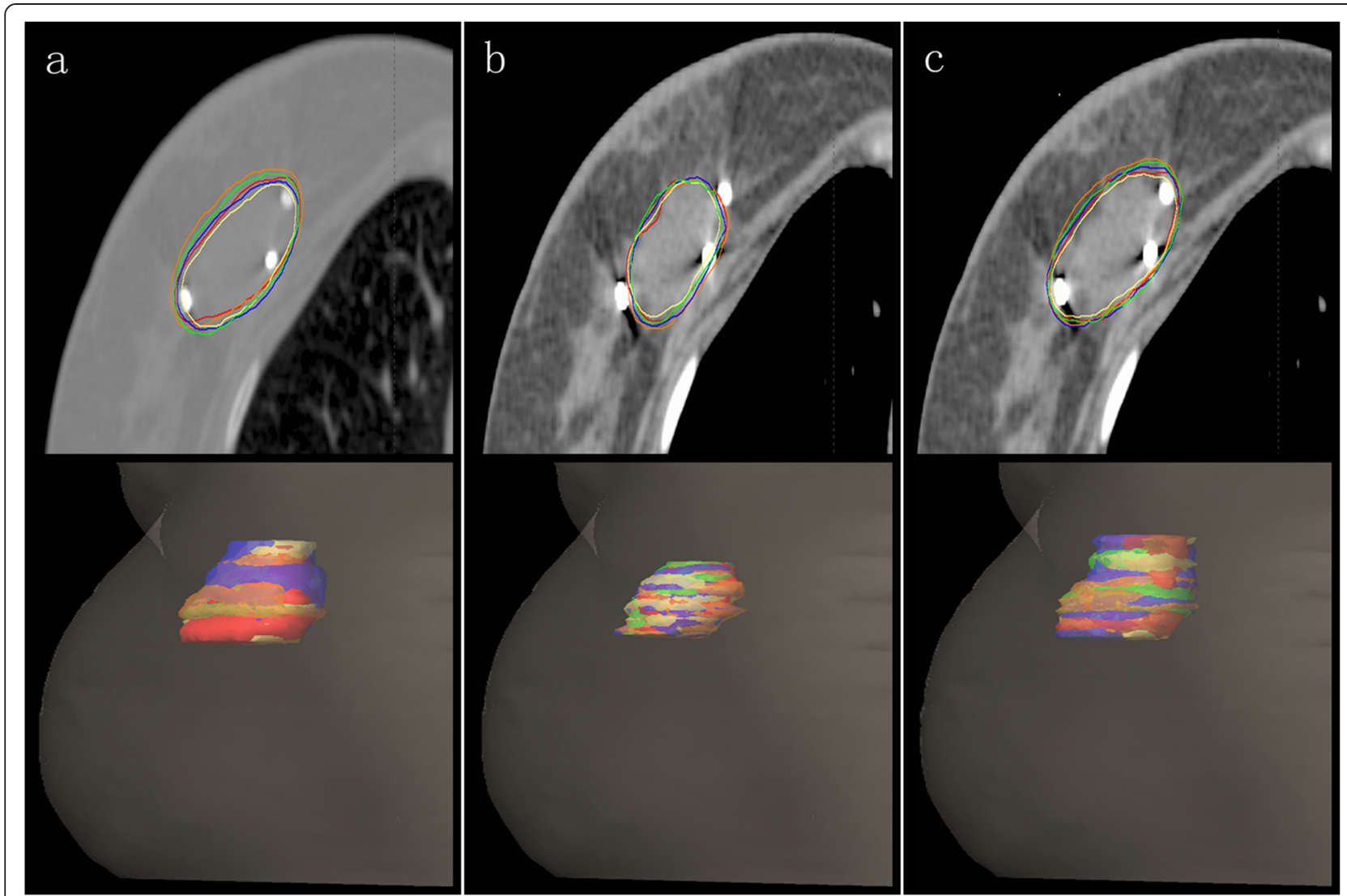

Figure 1 Single $C T$ slice and volumetric image of one patient with delineated $\mathrm{TB}_{\mathrm{C}}(\mathrm{a}), \mathrm{TB}_{\mathrm{S}}(\mathrm{b})$ and $\mathrm{TB}_{\mathrm{C}+\mathrm{S}}(\mathrm{c})$ of all 5 observers. $\mathrm{TB}_{\mathrm{C}}$, the $\mathrm{TB}$ delineated based on clips; $\mathrm{TB}_{\mathrm{S}}$, the TB delineated based on the seroma; $\mathrm{TB}_{\mathrm{C}+\mathrm{S}}$, the TB delineated based on both seroma and clips.

and $28.79 \mathrm{cc}$ (range 12.88-55.80), respectively. The volume variability between the $\mathrm{TB}_{\mathrm{C}}, \mathrm{TB}_{\mathrm{S}}$ and $\mathrm{TB}_{\mathrm{C}+\mathrm{S}}$ was statistically significant $(\mathrm{p}<0.05)$ (Table 2). Furthermore, the average duration from lumpectomy to 4DCT scan was 10 weeks (range, 3-16). The volume of $\mathrm{TB}_{\mathrm{C}}$ was similar to that of $\mathrm{TB}_{\mathrm{S}}$ for six patients during weeks $4-8$, the $\mathrm{TB}_{\mathrm{C}}$ was less than $\mathrm{TB}_{\mathrm{S}}$ in two patients during weeks $0-3$, and the $\mathrm{TB}_{\mathrm{C}}$ was larger than $\mathrm{TB}_{\mathrm{S}}$ for twelve patients during weeks 8-16.

The interobserver variability for $\mathrm{TB}_{\mathrm{C}}, \mathrm{TB}_{\mathrm{S}}$ and $\mathrm{TB}_{\mathrm{C}+\mathrm{S}}$ is listed in Table 2. The interobserver variability for $\mathrm{TB}_{\mathrm{C}}$ and $\mathrm{TB}_{\mathrm{C}+\mathrm{S}}$ was statistically significant $(\mathrm{p}=0.021,0.008)$. However, the interobserver variability for $\mathrm{TB}_{\mathrm{S}}$ was not statistically significant $(\mathrm{p}=0.867)$.

\section{COV}

The interobserver variability for COV is listed in Table 3. The interobserver variability for $\mathrm{COV}_{C}$ and $\mathrm{COV}_{\mathrm{C}+\mathrm{S}}$ was statistically significant $(p=0.002,0.015)$, but the interobserver variability for $\mathrm{COV}_{\mathrm{S}}$ was not statistically significant $(\mathrm{p}=0.061)$.

\section{MD}

Table 4 lists the differences in MD between the volumes delineated based on clips, seroma, and both clips and seroma in the EE phase. The interobserver variability for the $M D_{C}, M D_{S}$ and $M D_{C+S}$ was statistically significant $(\mathrm{F}=16.866, \mathrm{p}=0.000)$. There were also significant differences between $\mathrm{MD}_{\mathrm{C}}$ and $\mathrm{MD}_{\mathrm{S}}, \mathrm{MD}_{\mathrm{C}}$ and $\mathrm{MD}_{\mathrm{C}+\mathrm{S}}$, and $\mathrm{MD}_{\mathrm{S}}$ and $\mathrm{MD}_{\mathrm{C}+\mathrm{S}}(\mathrm{p}=0.000,0.032,0.008)$; the interobserver variability for $M D_{S}$ was smaller than that of $M D_{C}$ and $\mathrm{MD}_{\mathrm{C}+\mathrm{S}}\left(\mathrm{MD}_{\mathrm{S}}>\mathrm{MD}_{\mathrm{C}+\mathrm{S}}>\mathrm{MD}_{\mathrm{C}}\right)$.

\section{Discussion}

The accuracy of target volume delineation is critical for EB-PBI. The optimal target volume for EB-PBI remains to be established. Most reports define the tumour excision cavity or postoperative seroma as the target volume in treatment planning $[7,8,15]$. However, these studies also reported significant interobserver variation in delineating post-lumpectomy cavities. van Mourik et al. [16] investigated breast target volume delineations among thirteen observers in eight patients. They reported that the presence of clips or seroma reduced interobserver variability but that significant volumetric and spatial interobserver variability was observed in clinical target volume (CTV) even with the help of delineation guidelines. Therefore, reducing interobserver variability is a pressing issue. To improve delineation accuracy and consistency, 


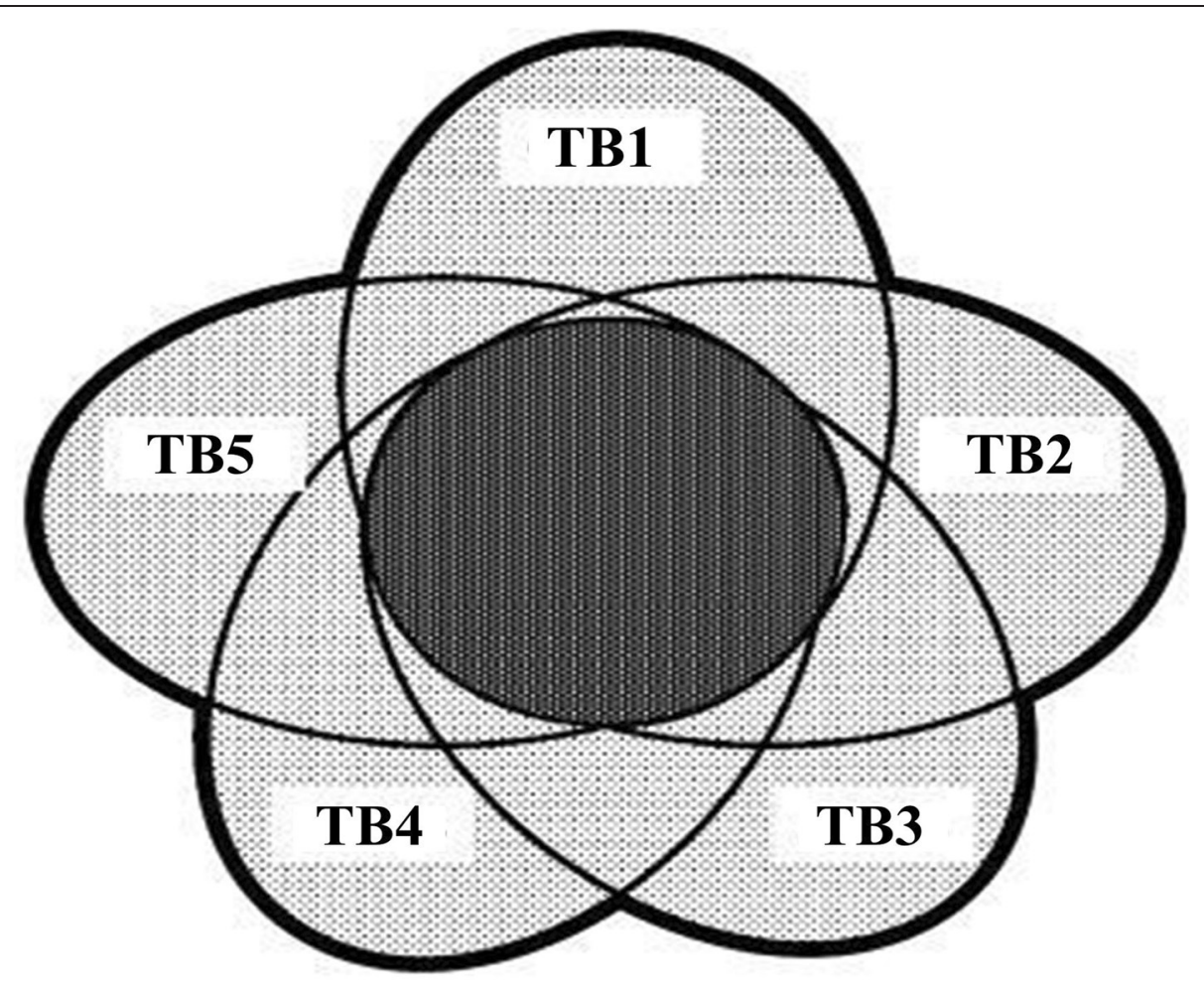

Intersection volume

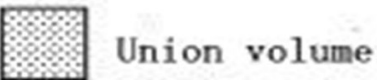

Figure 2 Mismatch between the TB delineated by five observers. The union volume is defined as the union of the five tumour beds, whereas the intersection volume is the intersection between the five tumour beds.

we selected patients with SCS $3 \sim 5$ and $\geq 5$ surgical clips to mark the boundaries of the lumpectomy cavity.

Seroma clarity and volume in the lumpectomy cavity decreased as a function of time from surgery to the CT scan. The use of the CT-based seroma to guide the EB-PBI target volume is difficult due to a lack of clearly defined standards. Kader et al. [6] selected 205 women with earlystage breast cancer to undergo planning $\mathrm{CT}$ after breast conserving surgery and found that the mean seroma volume decreased from $47 \mathrm{cc}$ to $30 \mathrm{cc}$ during postoperative weeks 3-8, stabilised during weeks 9-14 (mean $21 \mathrm{cc}$ ) and was involuted beyond 14 weeks (mean $9 \mathrm{cc}$ ). In our study, the average duration from lumpectomy to $4 \mathrm{DCT}$ scan was 10 weeks (range, 3-16). The volume of $\mathrm{TB}_{\mathrm{C}}$ approached the volume of $\mathrm{TB}_{\mathrm{S}}$ for six patients during weeks 4-8, and the $\mathrm{TB}_{\mathrm{C}}<\mathrm{TB}_{\mathrm{S}}$ in two patients during weeks $0-3$. However, after 8 weeks, the volume of $\mathrm{TB}_{\mathrm{C}}$ was larger than that of $\mathrm{TB}_{\mathrm{S}}$ for 12 patients. Therefore, given the magnitude and time trends of seroma volume and clarity loss, the optimal time to obtain the planning $\mathrm{CT}$ scan for $\mathrm{PBI}$ is within 8 weeks after surgery.

Surgical clips are not always consistent with the edge of seroma and the boundary of the lumpectomy cavity $[13,17]$. Ding et al [13] measured the three dimensional displacements of the $\mathrm{GTV}_{\mathrm{C}}$, the GTVs and the $\mathrm{GTV}_{\mathrm{C}+\mathrm{S}}$ and found that in the LR, AP and SI directions, the displacements were $0.9 \mathrm{~mm}, 1.05 \mathrm{~mm}$ and $1.20 \mathrm{~mm}$ for $\mathrm{GTV}_{\mathrm{C}} ; 0.80 \mathrm{~mm}, 1.05 \mathrm{~mm}$ and $0.80 \mathrm{~mm}$ for GTVs; and $0.90 \mathrm{~mm}, 1.20 \mathrm{~mm}$ and $1.40 \mathrm{~mm}$ for $\mathrm{GTV}_{\mathrm{C}+\mathrm{S}}$, respectively. In other words, the three dimensional displacements of $\mathrm{GTV}_{\mathrm{C}+\mathrm{S}}$ were greater than those of $\mathrm{GTV}_{\mathrm{C}}$ and $\mathrm{GTV}_{\mathrm{S}}$. Yang et al. [17] also measured the distance between surgical clips and the edge of the seroma in a coronal plane in women who underwent wide local excision of breast cancer and reported that the mean seroma edge extended beyond the clips by $0.3-0.5 \mathrm{~cm}$. This study indicates that the volume of $\mathrm{TB}_{\mathrm{C}+\mathrm{S}}$ delineated by observers was significantly larger than $\mathrm{TB}_{C}$ and $\mathrm{TB}_{\mathrm{S}}$. These results 
Table 1 The volumes of $\mathrm{TB}_{\mathrm{C}}, \mathrm{TB}_{\mathrm{S}}$ and $\mathrm{TB}_{\mathrm{C}+\mathrm{S}}$ (cc)

\begin{tabular}{|c|c|c|c|}
\hline Patients & $\mathrm{TB}_{\mathrm{C}}$ & $\mathrm{TB}_{\mathrm{S}}$ & $\mathrm{TB}_{\mathrm{C}+\mathrm{S}}$ \\
\hline 1 & $27.62(21.40-35.58)$ & $10.28(9.16-11.09)$ & $31.28(21.97-41.28)$ \\
\hline 2 & $30.20(24.22-32.13)$ & 13.80(12.34-15.27) & $32.58(24.93-36.33)$ \\
\hline 3 & $29.79(26.69-34.52)$ & $24.01(21.33-25.93)$ & $40.28(34.96-47.32)$ \\
\hline 4 & $45.13(42.98-47.03)$ & $41.80(38.63-45.81)$ & $55.80(48.73-67.71)$ \\
\hline 5 & $27.39(22.80-32.17)$ & $14.48(12.38-19.49)$ & $33.33(26.43-41.73)$ \\
\hline 6 & 24.94(20.59-31.99) & $32.48(30.30-37.82)$ & $47.61(44.20-59.24)$ \\
\hline 7 & $8.70(8.24-9.12)$ & $6.40(5.60-8.13)$ & $15.87(11.54-21.91)$ \\
\hline 8 & $16.91(14.17-22.80)$ & $15.62(11.16-20.84)$ & $19.14(17.55-20.01)$ \\
\hline 9 & $17.36(14.09-23.07)$ & $13.03(10.77-16.64)$ & $22.57(17.29-29.60)$ \\
\hline 10 & $19.43(16.62-24.45)$ & $27.46(24.15-29.68)$ & $40.21(34.14-47.77)$ \\
\hline 11 & 25.15(22.44-30.97) & $14.46(13.08-17.61)$ & $28.43(23.49-35.69)$ \\
\hline 12 & $24.26(21.78-30.37)$ & $25.20(24.21-26.71)$ & $33.87(31.53-40.34)$ \\
\hline 13 & $24.39(21.66-31.57)$ & $8.38(6.58-11.50)$ & $29.41(23.05-36.77)$ \\
\hline 14 & $15.02(11.93-23.00)$ & $4.73(3.37-7.38)$ & $17.64(12.88-24.60)$ \\
\hline 15 & 14.82(8.40-22.39) & $8.22(6.26-9.25)$ & 19.44(14.92-25.81) \\
\hline 16 & 16.89(13.07-26.14) & $5.67(4.12-7.84)$ & $20.09(12.57-28.15)$ \\
\hline 17 & 23.22(11.32-33.70) & $4.44(3.89-4.97)$ & $30.11(25.58-35.88)$ \\
\hline 18 & $15.68(12.31-22.72)$ & $6.55(4.6-9.12)$ & $19.19(13.37-25.41)$ \\
\hline 19 & $10.84(7.51-18.40)$ & $3.14(2.49-4.5)$ & 12.88(9.44-19.88) \\
\hline 20 & 21.83(16.64-28.61) & 7.13(5.97-8.75) & $26.16(20.08-33.18)$ \\
\hline Mean & 21.98 & 14.36 & 28.79 \\
\hline
\end{tabular}

Abbreviations: $\mathrm{TB}_{\mathrm{C}}$, the tumour bed delineated based on clips; $\mathrm{TB}_{\mathrm{s}}$, the tumour bed delineated based on the seroma; $\mathrm{TB}_{\mathrm{C}+\mathrm{S}}$, the tumour bed delineated based on both seroma and clips.

may be due to decreased seroma clarity and volume in the lumpectomy cavity from the time of lumpectomy to the 4DCT scan, as well as the variability between the $\mathrm{TB}_{\mathrm{C}}$, $\mathrm{TB}_{\mathrm{S}}, \mathrm{TB}_{\mathrm{C}+\mathrm{S}}$ regarding treatment margin.

Interestingly, we observed no significant differences between observers for $\mathrm{TB}_{\mathrm{S}}(\mathrm{p}=0.867)$ and $\mathrm{COV}_{\mathrm{S}}(\mathrm{p}=$ 0.061). This could be explained by the short average duration from lumpectomy to planning $\mathrm{CT}$ and because the SCS $3 \sim 5$ in the lumpectomy cavity improved the

Table 2 The interobserver variability for $\mathrm{TB}_{\mathrm{C}}, \mathrm{TB}_{\mathrm{S}}$ and $\mathrm{TB}_{\mathrm{C}+\mathrm{S}}(\mathrm{cc}, \mathrm{Mean} \pm \mathrm{SD})$

\begin{tabular}{llllll}
\hline & $\mathbf{T B}_{\mathbf{C}}$ & $\mathbf{T B}_{\mathbf{S}}$ & $\mathbf{T B}_{\mathbf{C}+\mathbf{S}}$ & $\mathbf{F}$ & $\mathbf{P}$ \\
\hline observer 1 & $19.87 \pm 9.14$ & $14.16 \pm 11.27$ & $25.94 \pm 12.19$ & 5.798 & 0.005 \\
observer 2 & $21.06 \pm 8.75$ & $14.26 \pm 10.97$ & $25.57 \pm 10.76$ & 6.815 & 0.002 \\
observer 3 & $20.01 \pm 7.8$ & $12.78 \pm 9.89$ & $24.88 \pm 10.43$ & 8.312 & 0.001 \\
observer 4 & $28.34 \pm 6.91$ & $14.07 \pm 11.74$ & $34.16 \pm 11.13$ & 19.565 & 0.000 \\
observer 5 & $20.61 \pm 9.07$ & $16.55 \pm 10.42$ & $33.41 \pm 13.80$ & 12.001 & 0.000 \\
F & 3.644 & 0.315 & 3.053 & & \\
P & 0.008 & 0.867 & 0.021 & & \\
\hline
\end{tabular}

Abbreviations: $\mathrm{TB}_{\mathrm{C}}$, the tumour bed delineated based on clips; $\mathrm{TB}_{\mathrm{S}}$, the tumour bed delineated based on the seroma; $\mathrm{TB}_{\mathrm{C}+\mathrm{S}}$, the tumour bed delineated based on both seroma and clips.
Table 3 The interobserver variability for COV $(\%$, Mean \pm SD)

\begin{tabular}{llll}
\hline & $\mathbf{C O V}_{\mathbf{C}}$ & $\mathbf{C O V}_{\mathbf{S}}$ & $\mathbf{C O V}_{\mathbf{C}+\mathbf{S}}$ \\
\hline observer 1 & $4.08 \pm 2.49$ & $4.3 \pm 2.13$ & $3.81 \pm 2.41$ \\
observer 2 & $4.04 \pm 1.33$ & $3.83 \pm 2.04$ & $3.23 \pm 0.71$ \\
observer 3 & $4.24 \pm 1.45$ & $5.31 \pm 2.85$ & $4.61 \pm 2.1$ \\
observer 4 & $2.66 \pm 1.42$ & $4.83 \pm 2.30$ & $2.69 \pm 1.05$ \\
observer 5 & $5.10 \pm 2.17$ & $3.42 \pm 1.55$ & $3.52 \pm 1.90$ \\
F & 4.591 & 2.331 & 3.332 \\
P & 0.002 & 0.061 & 0.015 \\
\hline
\end{tabular}

Abbreviations: $\mathrm{COV}_{C}$, coefficients of variability formed by $\mathrm{TB}_{\mathrm{C}} ; \mathrm{COV}_{\mathrm{s}}$, coefficients of variability formed by $\mathrm{TB}_{\mathrm{S}} ; \mathrm{COV}_{\mathrm{C}+\mathrm{s}}$, coefficients of variability formed by $\mathrm{TB}_{\mathrm{C}+\mathrm{s}}$.

visualisation of the surgical cavity. Landis et al. [8] reported similar results in patients of SCS 4 and 5 , as the average COM shift was $3 \mathrm{~mm}$ and $2 \mathrm{~mm}$, respectively, and the PVO was $77 \%$ and $87 \%$, respectively. Wong et al. [18] also reported that after reviewing contouring guidelines, the differences in seroma target volume (STV), $\mathrm{CTV}$, and planning target volume (PTV) were no longer statistically significant. Although Dzhugashvili et al. [9]

Table 4 The differences in MD between the volumes delineated based on clips, seroma and both clips and seroma

\begin{tabular}{|c|c|c|c|}
\hline patients & $M D_{c}$ & $\mathrm{MD}_{\mathrm{s}}$ & $M D_{c+s}$ \\
\hline 1 & 0.30 & 0.41 & 0.29 \\
\hline 2 & 0.37 & 0.51 & 0.39 \\
\hline 3 & 0.37 & 0.45 & 0.39 \\
\hline 4 & 0.31 & 0.69 & 0.49 \\
\hline 5 & 0.38 & 0.46 & 0.39 \\
\hline 6 & 0.38 & 0.58 & 0.37 \\
\hline 7 & 0.40 & 0.44 & 0.30 \\
\hline 8 & 0.34 & 0.46 & 0.49 \\
\hline 9 & 0.36 & 0.50 & 0.34 \\
\hline 10 & 0.36 & 0.63 & 0.46 \\
\hline 11 & 0.43 & 0.52 & 0.40 \\
\hline 12 & 0.45 & 0.59 & 0.51 \\
\hline 13 & 0.37 & 0.37 & 0.39 \\
\hline 14 & 0.29 & 0.43 & 0.30 \\
\hline 15 & 0.32 & 0.61 & 0.44 \\
\hline 16 & 0.31 & 0.41 & 0.39 \\
\hline 17 & 0.18 & 0.31 & 0.55 \\
\hline 18 & 0.24 & 0.48 & 0.42 \\
\hline 19 & 0.25 & 0.30 & 0.34 \\
\hline 20 & 0.27 & 0.63 & 0.45 \\
\hline $\bar{x} \pm s$ & $0.33 \pm 0.07$ & $0.49 \pm 0.11$ & $0.40 \pm 0.0$ \\
\hline
\end{tabular}

Abbreviations: $\mathrm{MD}_{\mathrm{C}}$, the ratio between the intersection volume and the union volume based on clips; $\mathrm{MD}_{\mathrm{s}}$, the ratio between the intersection volume and the union volume based on seroma; $\mathrm{MD}_{\mathrm{C}+\mathrm{S}}$, the ratio between the intersection volume and the union volume based on both clips and seroma. 
reported that the conformity index of TB delineation was significantly improved by the placement of surgical clips within the lumpectomy cavity, a higher level of interobserver concordance was observed by the five observers when the SCS was $3 \sim 5$ points in the lumpectomy cavity. These data suggest that interobserver variability in the delineation of TB based on seroma was not obvious when the SCS was $3 \sim 5$ points.

Although interobserver variability in the delineation of the TB based on seroma was minimal, the clinical reality could vary across regions. This was a retrospective study, and all the enrolled patients had undergone wide-local excision of breast cancer with full-thickness unstitching of the excision cavity. Full thickness closure of the excision cavity and oncoplastic surgical procedures are becoming more widely practiced in some regions, and these surgical methods could reduce the rate of seroma and its reliability as a marker of the TB. Therefore, patients should be given five or more surgical clips to reduce interobserver variability when only clips are used in clinical practice. Moreover, the placement of clips in the surgical cavity could be based on guidelines, and the duration from lumpectomy to 4DCT scan could be shortened.

Hurkmans et al. [19] reported that intra- and, to a greater extent, interobserver variability in the delineation of breast target volume on CT scans can be large. Both Dzhugashvili et al. [20] and Yang et al. [21] also reported interobserver variability (similar to the results presented here) in the delineation of the TB based on clips. These results can be explained by the fact that tissue stranding from the surgical cavity, proximity to muscle, dense breast parenchyma, and benign calcifications may be mistaken for surgical clips. Moreover, limited soft-tissue contrast on CT makes it an unreliable modality for detecting a layer of the image lacking surgical clips and when distinguishing between surgically induced densities and normal glandular breast tissue. Finally, the experience of the radiation oncologist and subjective determination of the location of the post-surgical cavity contribute to interobserver variability. Using a combination of information to more precisely define the $\mathrm{TB}$, such as surgical reports, clinical palpation of the surgical defect and CT-based planning, may decrease interobserver variability. Additionally, clear communication between the surgeon and radiotherapist, including diagrammatic explanations, are crucial for accurately targeting the TB.

Cover et al. [22] reported that when the EE phase was reviewed in the sagittal plane, gating would reduce the mean tumour mobility from $6.3 \pm 2.0 \mathrm{~mm}$ to $1.4 \pm 0.5 \mathrm{~mm}$. Moreover, 4DCT simulation scan can reduce motion artefacts [23,24]. Therefore, to investigate spatial mismatches of interobserver variability in the delineation of the TB based on different markers, the difference between the $M D_{C}, M D_{S}$ and $M D_{C+S}$ were further analysed and compared based on the end-exhalation phase. Our study found interobserver variability between the $\mathrm{MD}_{\mathrm{C}}$, $\mathrm{MD}_{\mathrm{S}}$ and $\mathrm{MD}_{\mathrm{C}+\mathrm{S}}$, as well as between the MDc and MDs, $M D_{C}$ and $M_{C+S}$, and $M D_{S}$ and $M_{C+S}$. Our results suggest spatial mismatch existed among observers in the delineation of the TB based on clips, the seroma, both the clips and seroma. Additionally, the MD of the seroma was larger than that of the clips as well as both the clips and seroma, and the MD of both the clips and seroma was larger than that of the clips alone (Table 4). However, the average CI reported by van Mourik et al. [16] was 0.53 , which was considerably higher than that in the present study. This difference is likely due to differing target volume and calculation methods. Landis et al. [8] and $\mathrm{Li}$ et al. [25] reported even higher $\mathrm{CI}$ values ranging from 0.73-0.75; however this analysis focused on the PTV instead of the $\mathrm{TB}$, the $\mathrm{CI}$ of which increases due to the larger volumes.

Image-guided techniques can improve clip and seroma localisation during treatment, potentially enabling the use of a smaller GTV-to-PTV margin. Ultrasound image guidance has also been investigated [26]. However, it is unclear if the margin is sufficient to account for interobserver contour variability. Further studies are needed to determine, whether contouring variability could result in an underdosing of the clips or seroma. Thus, it is imperative that future studies aiming to reduce margins from current treatment practice take interobserver contour variability into consideration.

\section{Conclusions}

The results of our study suggest that interobserver variability is smaller in the 4DCT delineation of the TB based on seroma compared with clips or both clips and seroma when the SCS was $3 \sim 5$ points and the number of surgical clips was $\geq 5$ in the lumpectomy cavity. Interobserver volume differences were observed between the TBs delineated based on surgical clips, and those delineated based on both the clips and seroma. This was also the case for spatial mismatch (MD), which was measured and analysed at the end-expiration phase. Optimising the time from lumpectomy to $4 \mathrm{DCT}$ scan is necessary to minimise interobserver variability in the delineation of the TB. If the time from lumpectomy to 4DCT simulation scan could be appropriately chosen, the delineation of the target volume based on seroma may be more reasonable in radiotherapy treatment planning.

\section{Abbreviations}

BCT: Breast-conserving therapy; PBI: Partial breast irradiation; EB-PBI: Externalbeam partial breast irradiation; SCS: Seroma clarity score; 4DCT: Four-dimensional computed tomography; COV: Coefficient of variation; MD: Matching degree; COM: Centre of mass; PVO: Percent volume overlap; El: End- inhalation; EE: End-exhalation. 


\section{Competing interests}

The authors declare that they have no competing interests.

\section{Authors' contributions}

BG and JBL designed the study, contributed to the data collection, and drafted the manuscript. WW, MX, QS, YJZ and CQL made important contributions in delineating the TB based on clips, seroma, and both clips and seroma. WW and YLG contributed to data collection and analysis. All authors read and approved the final manuscript.

\section{Acknowledgements}

This work was supported by Shandong Province Science and Technology Development Projects (2013WS0346).

\section{Author details}

${ }^{1}$ Department of Radiation Oncology, Shandong Cancer Hospital and Institute, Jiyan Road, Jinan, Shandong Province 250117, China. ${ }^{2}$ Medicine and Life Sciences College of Shandong Academy of Medical Sciences, Jinan University, Jinan, Shandong Province, People's Republic of China.

Received: 14 October 2014 Accepted: 25 February 2015

Published online: 13 March 2015

\section{References}

1. Clarke M, Collins R, Darby S, Davies C, Elphinstone P, Evans E, et al. Effects of radiotherapy and of differences in the extent of surgery for early breast cancer on local recurrence and 15-year survival: an overview of the randomised trials. Lancet Oncol. 2005;366:2087-106.

2. Litiere S, Werutsky G, Fentiman IS, Rutgers E, Christiaens MR, Van Limbergen $E_{\text {, et }}$ al. Breast conserving therapy versus mastectomy for stage I-II breast cancer: 20 year follow-up of the EORTC 10801 phase 3 randomised trial. Lancet Oncol. 2012;13:412-9.

3. Blichert-Toft M, Nielsen M, During M, Møller S, Rank F, Overgaard M, et al. Long-term results of breast conserving surgery vs. mastectomy for early stage invasive breast cancer: 20-year follow-up of the Danish randomized DBCG-82TM protocol. Acta Oncol. 2008;47:672-81.

4. Offersen BV, Overgaard M, Kroman N, Overgaard J. Accelerated partial breast irradiation as part of breast conserving therapy of early breast carcinoma: a systematic review. Radiother Oncol. 2009;90:1-13.

5. Njeh CF, Saunders MW, Langton CM. Accelerated partial breast irradiation using external beam conformal radiation therapy: a review. Crit Rev Oncol Hematol. 2012;81:1-20.

6. Kader HA, Truong PT, Pai R, Panades M, Jones S, Ansbacher W, et al. When is CT-based postoperative seroma most useful to plan partial breast radiotherapy? Evaluation of clinical factors affecting seroma volume and clarity. Int J Radiat Oncol Biol Phys. 2008;72:1064-9.

7. Kirby AM, Jena R, Harris EJ, Evans PM, Crowley C, Gregory DL, et al. Tumour bed delineation for partial breast/breast boost radiotherapy: what is the optimal number of implanted markers? Radiother Oncol. 2013;106:231-5.

8. Landis DM, Luo W, Song J, Bellon JR, Punglia RS, Wong JS, et al. Variability among breast radiation oncologists in the delineation of the postsurgical lumpectomy cavity. Int J Radiat Oncol Biol Phys. 2007;67:1299-308.

9. Dzhugashvili M, Tournay E, Pichenot C, Dunant A, Pessoa E, Khallel A, et al. 3D-conformal accelerated partial breast irradiation treatment planning: the value of surgical clips in the delineation of the lumpectomy cavity. Radiat Oncol. 2009;4:70.

10. Thureau S, Oden S, Mokaouim R, Mezzani-Saillard S, Clatot F, Hanzen C. Assessing the contribution of a standardized method in defining the tumor bed using surgical clips in breast cancer. Cancer Radiother. 2012;16:100-6.

11. Sharma R, Spierer M, Mutyala S, Thawani N, Cohen HW, Hong L, et al. Change in seroma volume during whole-breast radiation therapy. Int Radiat Oncol Biol Phys. 2009;75:89-93.

12. Shaikh T, Chen T, Khan A, Yue NJ, Kearney T, Cohler A, et al. Improvement in interobserver accuracy in delineation of the lumpectomy cavity using fiducial markers. Int J Radiat Oncol Biol Phys. 2010;78:1127-34.

13. Ding Y, Li J, Wang W, Fan T, Xu M, Shao Q, et al. Displacement of the lumpectomy cavity defined by surgical clips and seroma based on 4D-CT scan for external-beam partial breast irradiation after breast conserving surgery: a comparative study. Br J Radiol. 2013;86:20130416.

14. Geets X, Daisne JF, Arcangeli S, Coche E, De Poel M, Duprez T, et al. Interobserver variability in the delineation of pharyngo-laryngeal tumor, parotid glands and cervical spinal cord: comparison between CT-scan and MRI. Radiother Oncol. 2005;77:25-31.

15. Yang TJ, Tao R, Elkhuizen PH, van Vliet-Vroegindeweij C, Li G, Powell SN. Tumor bed delineation for external beam accelerated partial breast irradiation: A systematic review. Radiother Oncol. 2013;108:181-9.

16. van Mourik AM, Elkhuizen PH, Minkema D, Duppen JC, On behalf of the Dutch Young Boost Study Group, van Vliet-Vroegindeweij C. Multi-institutional study on target volume delineation variation in breast radiotherapy in the presence of guidelines. Radiother Oncol. 2010;94:286-91.

17. Yang Z, Chen J, Hu W, Pan Z, Cai G, Yu X, et al. Planning the breast boost: how accurately do surgical clips represent the CT seroma? Radiother Oncol. 2010;97:530-4.

18. Wong EK, Truong PT, Kader HA, Nichol AM, Salter L, Petersen R, et al Consistency in seroma contouring for partial breast radiotherapy: impact of quidelines. Int J Radiat Oncol Biol Phys. 2006;66:372-6.

19. Hurkmans CW, Borger JH, Pieters BR, Russell NS, Jansen EP, Mijnheer BJ. Variability in target volume delineation on $\mathrm{CT}$ scans of the breast. Int J Radiat Oncol Biol Phys. 2001;50:1366-72.

20. Dzhugashvili M, Pichenot C, Dunant A, Balleyguier C, Delaloge S, Mathieu MC, et al. Surgical clips assist in the visualization of the lumpectomy cavity in three-dimensional conformal accelerated partial-breast irradiation. Int J Radiat Oncol Biol Phys. 2010;76:1320-4.

21. Yang TJ, Minkema D, Elkhuizen PH, Heemsbergen W, van Mourik AM, van Vliet-Vroegindeweij C. Clinical applicability of cone-beam computed tomography in monitoring seroma volume change during breast irradiation. Int J Radiat Oncol Biol Phys. 2010;78:119-26.

22. Cover KS, Lagerwaard FJ, Senan S. Color intensity projections: a rapid approach for evaluating four-dimensional $C T$ scans in treatment planning. Int J Radiat Oncol Biol Phys. 2006;64:954-61.

23. Wang W, Li JB, Hu HG, Sun T, Xu M, Tan TY, et al. Evaluation of dosimetric variance in whole breast forward-planned intensity-modulated radiotherapy based on 4DCT and 3DCT. J Radiat Res. 2013;54:755-61.

24. Liao ZW, Guan XX, Li FY, He ZY, Xue M, Huang XY, et al. Accelerated partial breast irradiation: use of four-dimensional $C T$ for target localization and ssessment of intrafractional motion. Oncol Res. 2010;18:503-7.

25. Li XA, Tai A, Arthur DW, Buchholz TA, Macdonald S, Marks LB, et al. Variability of target and normal structure delineation for breast cancer radiotherapy: an RTOG Multi-Institutional and Multiobserver Study. Int J Radiat Oncol Biol Phys. 2009;73:944-51.

26. Berrang TS, Truong PT, Popescu C, Drever L, Kader HA, Hilts ML, et al. 3D ultrasound can contribute to planning $C T$ to define the target for partial breast radiotherapy. Int J Radiat Oncol Biol Phys. 2009;73:375-83.

\section{Submit your next manuscript to BioMed Central and take full advantage of:}

- Convenient online submission

- Thorough peer review

- No space constraints or color figure charges

- Immediate publication on acceptance

- Inclusion in PubMed, CAS, Scopus and Google Scholar

- Research which is freely available for redistribution

Submit your manuscript at www.biomedcentral.com/submit
C) Biomed Central 